\title{
Underground space development: setting modern strategies
}

\author{
D. Kaliampakos \& A. Benardos \\ National Technical University of Athens, \\ School of Mining \& Metallurgical Engineering, Greece
}

\begin{abstract}
Underground space development is an irreversible trend especially in urban environments. At this time the underground facilities have proved their usefulness in terms of efficiency and environmental friendliness. Nevertheless, in order to fully exploit the subsurface, new strategies need to be adopted in the whole context of city planning. This includes the introduction of new terms such as the valuation of the underground space, the adoption of integrated planning and zoning policies of the underground uses and the modernisation of the legal framework to incorporate the three-dimensional partition of the property. This paper discusses these issues, the adoption of which can lead to the development of a strategic underground plan, facilitating and further mobilising the hidden potential of underground space utilisation.
\end{abstract}

Keywords: valuation of underground space, planning and zoning of the subsurface, ownership rights of underground space.

\section{Introduction}

It has long been recognized that the utilization of the underground space represents a proficient choice to provide solutions to pressing urban problems. Nevertheless, underground projects have been rather focused, until the early 1970 s, on the development of transportation infrastructure [1]. Nonetheless, the construction of major transit projects such as metros and road tunnels is just a prelude for the true nature of underground development. The latter encompasses the relocation of several surface land uses or activities, in which installation is difficult, impractical, less profitable, or even environmentally undesirable on the ground level, into subsurface built environments. In the last couple of decades 
the engineering community has produced a great deal of exceptional underground projects that served their purpose with an increased efficiency compared to the respective surface solutions and proved the technological capabilities of the construction industry $[2,3]$. Even so, these projects have been developed in a passive manner, as they trailed the city's development and aimed at correcting or mitigating the problems caused by the surface expansion. Thus, a great deal of such underground projects were not part of integrated city planning, but they were rather aimed at solving locally existent problems. Hence, until now the true potential of underground structures is yet unexploited and the true challenge in current times is to pass to the mature phase of underground urban utilisation through the incorporation of a strategic multi-disciplinary vision about the use of subsurface space as an integral part of future physical planning and zoning [4].

In the new century, the development of mega-cities, coupled with more pressing needs for a better urban environment, will raise demands for enhanced underground solutions [5-7]. Demands that cannot be met, if either the current planning mode is to be followed without correcting its mistakes or the urban underground resource is consumed without any form of control.

All the above put forth more challenging tasks, like the efficient and sustainable utilization of the subsurface, the adoption of underground solutions completely replacing several aboveground uses - as the common practice, and the introduction of novel tools capable of measuring the effect that underground space development will have on modern cities. The paper analyzes the new driving forces for strategic subsurface planning and furthermore examines the issues that need to be addressed and adjusted for underground space development so as to meet the requirements of the new era.

\section{Urbanisation - the main driving force for underground development}

Interest in underground development, especially in urban areas, is constantly increasing internationally. As noted, the main driving force behind the process is the continuously growing urban areas, coupled with the demand for high quality environmental conditions. Unless, one or both these factors cease to exist, the exploitation of the urban subsurface will undoubtedly be in the centre of attention.

One of the most remarkable features of the previous century was the growth of the global population. In the beginning of the 20th century, the world population amounted to 1.6 billion approximately. Today global population is about 6.5 billion and it is estimated that it will reach 9 billion by 2030 . Probably more interesting are the development of urban centres and the unparalleled growth of the urban population. In 1800, the percentage of the total population that lived in urban regions was only 3\%. It was not until 1820 that London had became the first city that exceeded 1 million residents; in 1900 the number of cities with a population of 1 million residents amounted to 11 , whereas the percentage of the total population that lived in urban regions had risen to $14 \%$. 
From this point on the development was very fast. In 1950 word population was 2.5 billion and 83 cities had population above 1 million residents, whereas only two cities, London and New York, measured above 10 million residents. The corresponding figures for the urban population are 731 millions in 1950 and 3.1 billion in 2005 . It is observed, that while the total population increased by $156 \%$, in the last 50 years, the urban population increased by $333 \%$ during the same time [8]. Today, $49.2 \%$ of world's population live in urban regions. According to a recent UN research [9] it is estimated that the world urban population will reach 4.98 billion by 2030 compared to 2.86 billion in 2000 , representing about the $60 \%$ of the world population. In the developed countries the percentage of urban population is significantly higher $(76 \%)$ compared to the developing ones $(40 \%)$. The latter, however, present higher rates of urbanization. Table 1 presents the forecast for the development of Europe and Northern America's population between 2000 and 2030. It is observed that in 2030 more than $80 \%$ of the total population, in both continents, will reside in urban areas. Furthermore, what is worth noticing is that, while the total population of Europe is expected to be reduced by approximately $8 \%$, the urban population is estimated to be increased by roughly $1 \%$.

Table 1: $\quad$ Population growth forecast for Europe and North America [8].

\begin{tabular}{|l|c|c|c|c|}
\hline & \multicolumn{2}{|c|}{2000} & \multicolumn{2}{c|}{2030} \\
\hline & North America & Europe & North America & Europe \\
\hline Total Population & 314.000 .000 & 727.000 .000 & 396.000 .000 & 670.000 .000 \\
\hline Urban Population & 243.000 .000 & 534.000 .000 & 335.000 .000 & 540.000 .000 \\
\hline \% urban/total pop. & 77,4 & 73,5 & 84,6 & 80,6 \\
\hline \% total pop. growth & & & 26,11 & $-7,84$ \\
\hline$\%$ urban pop. growth & & & 37,86 & 1,12 \\
\hline
\end{tabular}

Such has been the growth of urban agglomerations that new terms have been developed to describe the phenomenon as, for example, the term "megacity" that refers to cities with a population of over 5 million residents. Unfortunately all these have come at a cost. It is widely accepted that the lack of free surface space, the sorely high land prices and the deterioration of the environmental conditions are just a few of the repercussions of urbanization [10].

Initially, urban planning opted for the obvious solution, namely spatial expansion, in order to ameliorate these problems. However, as the city's borders were continuously expanding, consuming greedily free space the result proved twofold. On the one hand, the line that distinguishes urban and suburban areas grew thinner and, on the other hand, soon it became apparent that the urban sprawl resulted only in the immigration of the problems to adjacent areas [11]. At this point, sooner or later, depending generally on a country's development, a new alternative emerged: the development of underground space. Among the main advantages deriving from the utilization of underground space are the release of space on the surface, the preservation of "sensitive" areas, such as historical city centres, archaeological sites and considerable energy savings. At 
the same time the installation of hazardous processes (industrial uses, hazardous waste treatment and disposal, etc.) below ground level ensures minimum risk and disturbances (visual impact, noise pollution, odours, etc.) generated by these activities [2].

\section{Going underground with a plan}

In order to fully exploit the underground the issue of underground land use planning should be brought forward. That means that there should be an overall long-term planning regarding the siting of the underground facilities along with their prioritisation in terms of importance, feasibility and environmental performance. This planning integrated with the possible identification of the development needs can assist in proactively and efficiently construct the right underground structure in the most appropriate place [12]. As a result the optimisation of its positive impacts could be achieved without at the same time jeopardising the misuse or irrational consumption of the underground space.

Of course these policies are not easy to be implemented. Nevertheless a boost in that direction could be made if the following preparatory steps are to be taken:

- The assignment of a value to the underground space.

- The comprehensive investigation and mapping of the underground space, especially in urban areas.

- The adjustment and modernisation of the legislative framework governing the underground space.

\subsection{The value of underground space}

In the majority of cases underground space is considered to be a public good and a zero value is assigned to it [13]. That means that its "consumption" could take place without paying virtually any cost at all. But let's consider a case where the existence of an underground space in a particular area can have an adverse effect to the construction cost of another underground structure that is proposed to be build adjacent, over or under it. One can argue that the excess cost (e.g. for additional or bypass works, or better support measures) can be considered as the price to pay for the already consumed underground space. This is only a simple example showing that if the value of underground space is ignored, incorrect or misleading assumptions could be made in the planning of the subsurface. Thus it might lead to a non-optimum utilisation, which in turn, could reduce many of the benefits of underground structures.

The urbanisation, as discussed earlier, leads to the development of more underground structures. This increase in the consumption of subsurface resources is gradually transforming the underground medium from a free good into a commodity. Therefore, underground space mandates a value to be assigned at it. Nevertheless, this is a very complicated task, due to the theoretical and practical problems involved. On the surface the methods and techniques for appraising land value and the value of real estate property in general have been long used and coupled with the well-defined proprietary rights. Such methods for 
appraising underground space value do not currently exist and their absence further aggravates the situation. With the exception of a few cases, where the value of underground space can be inferred, such as in the case of underground car parks, in the majority of underground works the value of the subsurface remains an open question.

As a consequence, more often than not, underground space value appears to be a missing factor in underground development and planning. Ignoring this parameter may seriously delay, in many cases, any underground development. On the other hand, it can lead to an over-consumption of shallow subsurface space, adding more confusion to the often chaotic current conditions, and unjustifiable under-consumption of deeper underground space [13].

Another interesting remark is that many researchers argue that underground space shares many features with non-renewable resources. This is due to the fact that the use of underground space is practically irreversible. Unlike structures aboveground, which can be demolished and rebuilt differently, underground works, in almost all of the cases, cannot be demolished. Underground development changes permanently the existing conditions and there is no realistic way of re-establishing the initial conditions. Therefore, its "consumption" should be done after careful and detailed planning in order for the society to reap the benefits of underground development [14].

As a general rule, the economic feasibility of underground works is judged on the grounds of the comparison between underground and surface construction cost, plus the land cost. However, this comparison reflects only a part of the truth, as the impacts of the planned structures to the environment or the society, expressed in monetary terms are not incorporated in the analysis. Therefore, in order to provide an answer regarding the social benefits of underground solutions, it is necessary to evaluate all the benefits and costs, including the socalled externalities. In other words, underground solutions should be assessed on the grounds of social cost-benefit analysis, using bottom-up approaches and environmental valuation methods. Although there are difficulties in environmental valuation, internationally the use of environmental economics in project appraisal has significantly increased, since it results in better decisions [15].

Towards this direction, both, primary research, based on revealed methods (e.g. Travel Cost and Hedonic Pricing) and preference methods (Contingent Valuation), as well as Benefit Transfer studies have been conducted. Empirical evidences show that the scarcity of free space, the need to protect existing green areas from further degradation and the will to enhance living conditions in modern urban centres tend to increase the cost-effectiveness of underground development and, consequently, their net social benefits.

To illustrate the above with an example let us consider the case of an underground parking facility. This plan allows for a corresponding increase of free space in the surface, which could be developed as an urban recreational green area. According to a research by Damigos and Kaliampakos [16], it was estimated that an urban park of $20,000 \mathrm{~m}^{2}$ in a densely populated region of Athens affects the dwelling prices at a range between $1-4$ blocks. Within this 
zone, a property attracts a premium of $14 \%$ up to $31 \%$. More specific, given that the average unit price of an apartment, in the case examined, was about 1,320 $€ / \mathrm{m}^{2}$, the value of the green space capitalized in property prices of the surrounding dwellings ranged between 185 up to $409 € / \mathrm{m}^{2}$. It is apparent that in the comparison between an underground facility and the equivalent surface one, apart from the construction, the operational and the land cost, the benefits created by the green areas should also be considered. In this way, if the value of environmental goods and services is taken into account, the advantages of the underground solution would be revealed on strict financial grounds as well.

Nishi et al. [17] presented a similar case in 2000. The authors used a questionnaire in order to establish the residents' Willingness To Pay - WTP to prevent any surface construction that would result in visual degradation of the landscape. The researchers interviewed residents in the cities of Hakodate, Nagoya, Kyoto and Kobe. The results showed that residents were willing to pay $\$ 77.5 /$ year/person to preserve the view.

\subsection{Mapping and planning of underground space}

The vision for underground space development, especially in congested urban areas, mandates for a detailed mapping of the subsurface. Particular attention should be paid to special geological opportunities in terms of rock/soil type and easy access from the surface to the favourable locations. In this issue, there are some notable examples where city or state authorities have collected geological information. More particularly, in Japan, three-dimensional soil-structure data systems have been developed by governmental agencies and are addressed as a part of a GIS [18]. The information, primarily intended for specialists in geology, is also used by engineers in charge of ground surveys. The geological survey of Japan has issued a digital geo-science map, while the Tokyo Metropolitan has carried out geological surveys in conjunction with building construction work and urban base improvement projects. The extensive information from these surveys is incorporated in a relational database and can be retrieved and graphically present borehole, and groundwater data. In Finland, the geoinformation is provided by soil and bedrock maps, as well as by the topographical maps provided by the Geological Survey of Finland and local authorities. In Helsinki [19], the Helsinki Geotechnical Database has been established from 1955 and at present contains detailed information on 200,000 site investigation points including sampling and laboratory tests, representing a combined cost of investigation amounting approximately 45 million Euros.

Such geological and geotechnical information contain crucial data nevertheless, it represents only the first step towards the ultimate goal of efficient underground space utilisation. In order to carry forward the development and utilization of underground spaces systematically, a subsurface map that can be used in the development planning and operation stages is necessary. The concept of underground mapping is not to be only limited to geo-information but rather implies that the full resource potential of urban underground must be investigated and recorded. The mapping of underground space should encompass its interaction with the surface buildings and the existing structures along with a 
land use policy for the underground, as already enforced in typical surface space. Therefore, engineers and urban planner should co-ordinate their actions, aiming at:

- identifying current uses of underground facilities and investigate possible future underground uses and needs in the urban environment

- determining the areas with a high potential for the use of underground space

- recognizing the development scenarios that might encourage or impede the use of underground space.

Stakeholders should decide on the short and long - term urban planning needs and by utilising the data regarding the prevailing geological conditions threedimensional maps of the subsurface utilisation should be drawn. Consequently, the identification and the promotion of appropriate zoning of several underground use types will be available, along with the time frame for their construction and operation life. Prioritizing the development of conflicting or overlapping underground structures is also of major importance, as well as the recognition of areas where the underground space should be reserved for future needs.

\subsection{Ownership of underground space}

Legal and administrative restrictions on the development and use of underground space may act as significant barriers to the use of this resource. One of the most significant issues is the proprietary rights of the underground space. Since national territories, local jurisdictions and private ownership are normally defined in terms of boundaries of surface land area, it is necessary for underground space to define how surface ownership extends downwards to the underground and upwards to the sky. Since the roman times, it has been accepted by most western laws that: "Cujus est solum, ejus est usque ad coelum et ad inferos - To whomsoever the soil belongs, he owns also to the sky and to the depths" [20].

Since underground space may allow functions to occur within the space independent of the surface land above, questions often arise as to what extent surface land use regulations should apply to the development of underground space. Laws that control land ownership vary among countries, resulting in a state of uncertainty regarding the ownership of subsurface. According to a survey carried out by ITA's WG4 [20] four types of proprietary rights are found to exist:

- unlimited ownership to the centre of the earth

- as far as reasonable interest exists

- only to a limited depth

- the underground is also publicly owned, as private land ownership is almost nonexistent.

The underground space ownership with respect to non-mining activities, especially in urban areas, where several conflicts exist between private and public interests, remains so far unsolved in the majority of the countries. A few of them however have recognised the need to revise their legislation in terms of 
land ownership and started investigating three-dimensional delimited real estate. For example Oslo (Norway), has already adopted the three-dimensional real estate model [7]. In Japan the land ownership hindered the realisation of major underground public projects and in 2001 a new law was enforced which limited the private land ownership to the depth of $50 \mathrm{~m}$ (including deep foundations), while the state owns and manages the subsurface below $50 \mathrm{~m}$, the "deep underground". In the case of the city of Montreal [21] it is widely accepted that the development of the underground city of Montreal would have not been accomplished, unless urban planners had decided to stratify the property rights both vertical and horizontal, etc.

Nowadays, it is more pressing than ever for national governments to update their legal framework related to ownership of subsurface space, so that development of underground infrastructure will be facilitated. The legal responsibilities of owners of underground space and other affected parties should be clearly defined and this can be made possible either by enabling the threedimensional property or by other amendments (e.g. subsurface volumetric trading).

\section{Conclusions}

As the trend for underground development firmly established its position in urban planning and the experience gained from underground projects gradually dispersed any doubts concerning the advantages and the superiority of underground structures against contemporary urban problems, building in the subsurface becomes the first choice.

Advances in fields such as rock mechanics, excavation and support of underground structures will undoubtedly enable the construction of more complex and difficult underground projects even in cases when building underground was previously not considered as an option. This constitutes the necessary starting point, still, the strategic vision towards the optimal underground space utilization needs modern strategies to reflect the new prevailing conditions. Issues like the valuation of the subsurface recourse, the mapping and zoning of underground uses and the ownership rights of the underground should be brought forward and resolved in order to have a new, clear framework that will eventually lead to the promotion the subsurface utilisation.

\section{References}

[1] Mavrikos, A.A., \& Kaliampakos, D.C., Underground development in urban areas: the birth, the evolution and the perspectives of the trend. Proc. of the 4th Int. Conf. on Urban Regeneration and Sustainability "The Sustainable City", Tallinn, Estonia, 17-19 July, 2006.

[2] ITA, Underground works and the environment, Report of the Working Group on Underground Works and the Environment, International Tunnelling Association, 1998. 
[3] Besner, J., The sustainable usage of the underground space in metropolitan area. Proc. of the 9th ACUUS Int. Conf. "Underground Space: a Resource for Cities”, Turin, Italy, 14-16 November 2002.

[4] Ronka, K., Ritola, J., \& Rauhala, K., Underground Space in Land-Use Planning. Tunnelling and Underground Space Technology, 13(1), pp.3949, 1998.

[5] Damigos, D., Benardos, A., \& Kaliampakos, D., The space beneath: Developing the new human-friendly cities. Proc. 1st Int. Conf. Advances in Mineral Resources Management and Environmental Geotechnology, 7-9 June, Crete, pp. 641-646. 2004.

[6] Maire, P., Pascal Blunier, P., Parriaux, A., Tacher, L., Underground planning and optimisation of the underground resources' combination looking for sustainable development in urban areas. Proc. Workshop "Going Underground: Excavating the Subterranean City", 21-22 September, Manchester, UK, 2006.

[7] Landahl, G.M., Planning of Underground Space, eds Franzèn T., Bergdahl, S. and Nordmark, A., Proc. of the Int. Conf. on Underground Construction in Modern Infrastructure, Stockholm, Sweden, June 7-9, pp. 95-100, 1998.

[8] Geohive, www.geohive.com

[9] UN-HABITAT, 2004/05 Report, State of the world's cities, www.unhabitat.org

[10] Kaliampakos D., \& Mavrikos A., Underground Development in Greece: History, Current Situation and Trends. Proc. 1st Int. Conf. Sustainable Development and Management of the Subsurface, 5-7 November, Utrecht, 2003.

[11] Mavrikos, A.A., \& Kaliampakos, D.C., Appraising the environmental advantages of underground storage facilities in Athens, Greece. Proc. of the 11th ACUUS Int. Conf., "Underground Space: Expanding the Frontiers", 10-13 September, Athens, Greece, pp. 267-272, 2007.

[12] Mavrikos, A.A., \& Drakouli E., Incorporating underground space in urban planning. Proc. of the 11th ACUUS Int. Conf., "Underground Space: Expanding the Frontiers", 10-13 September, Athens, Greece, pp. 317-322, 2007.

[13] Riera, P., \& Pasqual, J., The importance of urban underground land value in project evaluation: a case study of Barcelona's utility tunnel, Tunnelling and Underground Space Technology, 7(3), pp. 243-250, 1992.

[14] Sterling, R.L., \& Godard, J-P. Geoengineering considerations in the optimum use of underground space. ITA-AITES Position Papers, 2001.

[15] Damigos D. \& Kaliampakos D., Economic valuation of mined land reclamation: An application of Individual Travel Cost Method in Greece. Proc. of the International Conference, SGEM 2001: Modern Management of Mine producing, Geology and Environment Protection, Bulgaria, 2001.

[16] Damigos, D. \& Kaliampakos, D., Environmental Economics and the Mining Industry: Monetary Benefits of an Abandoned Quarry Rehabilitation in Greece. Environmental Geology, 44(3), pp. 356-362, 2003. 
[17] Nishi, J., Tanaka, T., Seiki, T., Ito, H., \& Okuyama, K., Estimation of the value of internal and external environment in underground space use, Tunnelling and Underground Technology, 15(1), pp. 79-89, 2000.

[18] Takasaki, H., Chikahisa, H., \& Yuasa, Y., Planning and Mapping of Subsurface Space in Japan. Tunnelling and Underground Space Technology, 15(3), pp. 287-301, 2000.

[19] Vahaaho, I., From geotechnical maps to three-dimensional models. Tunnelling and Underground Space Technology, 13(1), pp. 51-56, 2000.

[20] Sterling, R., Legal and administrative issues in underground space use. A Preliminary Survey of Member Nations of the International Tunnelling Association, International Tunnelling Association, 1990.

[21] Escobar, M., The Next Urban Frontier - The Inner City and the Role of the Evolution of Real-Property Law in the 21st Century - A Montreal Perspective, Proc. of the 9th International Conference, Urban Underground Space: a Resource for Cities, 14-16 November, Turin, Italy, 2002. 